\title{
Safety Considerations Regarding to the Shielding of Electric Fields during High Voltage Live-line Maintenance
}

\author{
G. Göcsei, I. Berta, B. Németh \\ Budapest University of Technology and Economics, \\ High Voltage Laboratory \\ Hungary, 1111 Budapest, Egry József u. 18. \\ Phone: +36 14633236 \\ e-mail: gocsei.gabor@vet.bme.hu
}

\begin{abstract}
Live-line maintenance (LLM) has several technical and economic benefits. Planned works can be executed without any consumer disturbance, while the network is energized. Strict regulations regarding to the working method, well-educated workers and well-considered safety factors ensures the high level of safety of this technology. Although statistics show that the number of injuries is lower than in case of de-energized works, the unseen short- and long term effects of electric and magnetic fields also have to be taken into consideration.
\end{abstract}

Keywords: live-line, maintenance, electric, field

\section{The future of maintenance}

Live-line maintenance can be referred as the "future of maintenance". It is more and more popular, because of its technical and economic benefits and is preferred from both the side of the Distribution/Transmission System Operator (DSO/TSO) and the consumers. This technology ensures planned reparation and maintenance works to be executed while the network is energized. No need of switching-off increase consumer satisfaction and is advantageous from the side of the operator as well [1].

\subsection{Technical benefits}

However most of the high voltage networks are looped to ensure proper safety factors of electrical energy distribution, there might be special conditions when switching-off a given line leads to violate "rule $n-1-m$ ", where $n$ is the sum of the elements of the network and $m$ is the number of elements which are out of operation because of a planned maintenance. In case of the failure of a specific element, network shall still be operating reliably. 
In case of switching-off a given line for the purpose of de-energized work, current paths increase; increased length and current also increases losses. Operation of circuit breakers, disconnectors, etc. shortens the service period of the given equipment while degradation increases.

\subsection{Economic benefits}

Economic losses caused by de-energized works and not occurring during any kind of live-line work are the sum of the cost and fines of energy not served. Fines usually consists predictable and non-predictable parts. Non-predictable part (e.g. as a result of rainstorms, icing, snow, etc.) cannot been foreseen. Cost of predictable part can be minimized by keeping the length of de-energized periods as low as possible. Consumer satisfaction as an indicator of service quality can also be expressed as a financial quantity.

\section{Live-line work related risks}

Speaking about safety of any kind of live-line work, the most important question is the protection against electric shock. Depending on different technologies applied at different voltage levels it can be executed by different ways: rated insulating materials (e.g. blankets, gloves, rods, etc.) or air - as an insulator - can also be used. In case of high voltage live-line maintenance barehand method is widely applied. The main principle of this method is that keeping the proper distances prescribed can guarantee to avoid electric shock caused by touching or approaching specific network elements with different potentials. Safety distances include a flashover/breakdown component and an ergonomic component (as a function of voltage level). Switching and lightning overvoltages are also taken into consideration and worst-case scenarios are assumed. Because the most critical cases regarding to transmitted power, voltage level, current load, etc. occur during high voltage live-line maintenance the main topic of this paper is to focus on this field of LLM. Regarding to power arcs - might be caused as a result of multiple failures - thermal effects are the most critical. Electric shock also may lead to fatal injuries as well. The examination of these dangers and the analysis of the related risks is out of the scope of this paper. The unseen - especially long-term - effects of extra-low frequency (ELF) electric and magnetic fields is inspected instead.

\section{Electric and magnetic field during high voltage LLM}

Electric and magnetic fields together are often referred as "electromagnetic fields" but from the aspect of the topic it is essential to clarify the basic differences between electric, magnetic and electromagnetic fields. Static electric/magnetic fields have two criteria to meet: drift currents have to be negligible compared to the total current density and the length of the line cannot been in the same scale than the wavelength. In case of typical power lines with a frequency of $50 \mathrm{~Hz}$, typical wavelength is $6000 \mathrm{~km}$, which is significantly longer than the length of any conventional AC power line regardless of voltage level. Drift currents are determined by the material and frequency; in case of aluminium-steel conductors with a typical conductivity of $10^{7} \Omega / \mathrm{m}$, critical frequency can be determined and is about $10^{17} \mathrm{~Hz}$. 


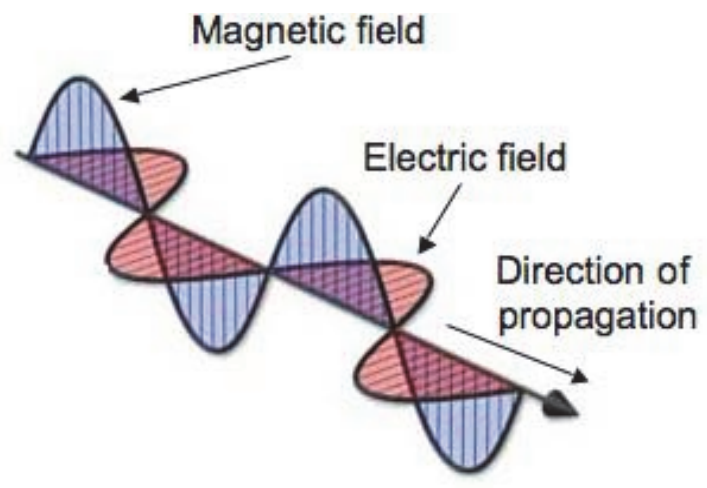

Figure 1. Electromagnetic wave [2]

Both length- and material-related conditions shows that in case of industrial frequency and conventional material selection, none of the fields around power lines can be handled as an electromagnetic field; electric and magnetic fields - and the effects of them - have to be taken into consideration separately from each other. These properties are often summarized by referring them as extra low frequency (ELF) fields - usually below a frequency of $100 \mathrm{kHz}$. Both electric and magnetic fields have several short- and long term health effects above a given limit. These limits are defined by the International Commission on Non-Ionizing Radiation Protection (ICNIRP). Because of the nonionizing nature of these kinds of exposures, exposure doses cannot been defined. Current values together with the previous limits (before 2010) are summarized in Table 1.

Table 1. Current and previous limits of ICNIRP regarding to ELF electric and magnetic fields [3], [4], [5]

\begin{tabular}{|c|c|c|c|c|}
\hline & \multicolumn{2}{|c|}{$\begin{array}{c}\text { Electric field strength } \\
\text { limit }[\mathrm{kV} / \mathrm{m}]\end{array}$} & \multicolumn{2}{|c|}{$\begin{array}{r}\text { Magnetic field strength limit } \\
{[\mu \mathrm{T}]}\end{array}$} \\
\cline { 2 - 5 } & $\begin{array}{c}\text { Before } \\
2010\end{array}$ & Currently & Before 2010 & Currently \\
\hline Public (24 h/day) & 5 & $\mathbf{5}$ & 100 & $\mathbf{2 0 0}$ \\
\hline Occupational (8h/day) & 10 & $\mathbf{1 0}$ & 500 & $\mathbf{1 0 0 0}$ \\
\hline
\end{tabular}




\section{ELF electric fields}

\subsection{Health effects of ELF electric fields}

Short-term effects of ELF electric fields above the valid exposure limits are described as a discharge on the skin of the human body which may make any activity requiring high accuracy hard. This is the main reason of the application of conductive clothing in case of barehand method. However electric fields themselves do not have any direct long-term effects on the human body, drift currents occurring as a result of the variation of electric field has similar effects as the above-the-limit magnetic fields categorized as possibly carcinogenic to humans (2B) by the International Agency for Research on Cancer (IARC) of World Health Organization (WHO) [6].

\subsection{Protection against ELF electric fields}

A Faraday-cage is an enclosed metal surface. Theoretically inside an ideal Faradaycage without any openings electric field strength is zero from outer source. Conductive clothing worn by the workers during high voltage live-line maintenance as an essential accessory of barehand method is acting as a Faraday-cage against ELF electric fields in the vicinity of the phase conductors of high voltage power lines. Typically the material of these clothing is a special mixture of a flame-retardant textile and conductive metal threads which guarantee proper screening efficiency.

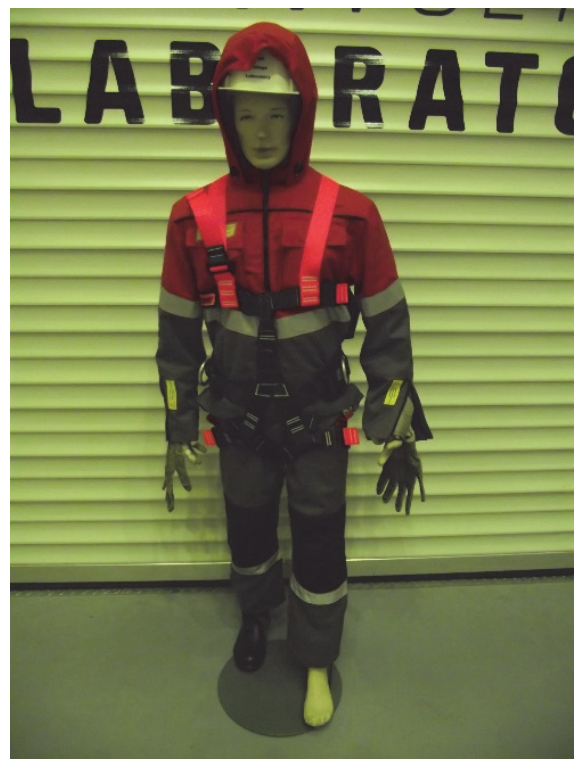

Figure 2. Conductive clothing during an inspection in the High Voltage Laboratory of Budapest University of Technology and Economics 
Effectiveness of a conductive clothing is currently determined by the ratio of two currents. Capacitive currents flow through both in the conductive clothing and the mannequin with a conductive surface placed in high electric field. There are several issues [7] regarding to the current arrangement of the valid standard [8]. There might be practical cases with above-the-limit electric fields inside the clothing, while the clothing pass the current ratio-based inspection of the standard. Laboratory inspections with direct electric field strength measurement in the High Voltage Laboratory of Budapest University of Technology and Economics (BUTE) prove that inside a conductive clothing without any face mesh ELF electric field strength may be above the current limits defined by ICNIRP. Results for electric field strength values at different voltage levels are shown in Fig. 3. The distance between the conductor and the mannequin was $30 \mathrm{~cm}$, while the conductive clothing was energized (practical case after the connection of the potential clamp).

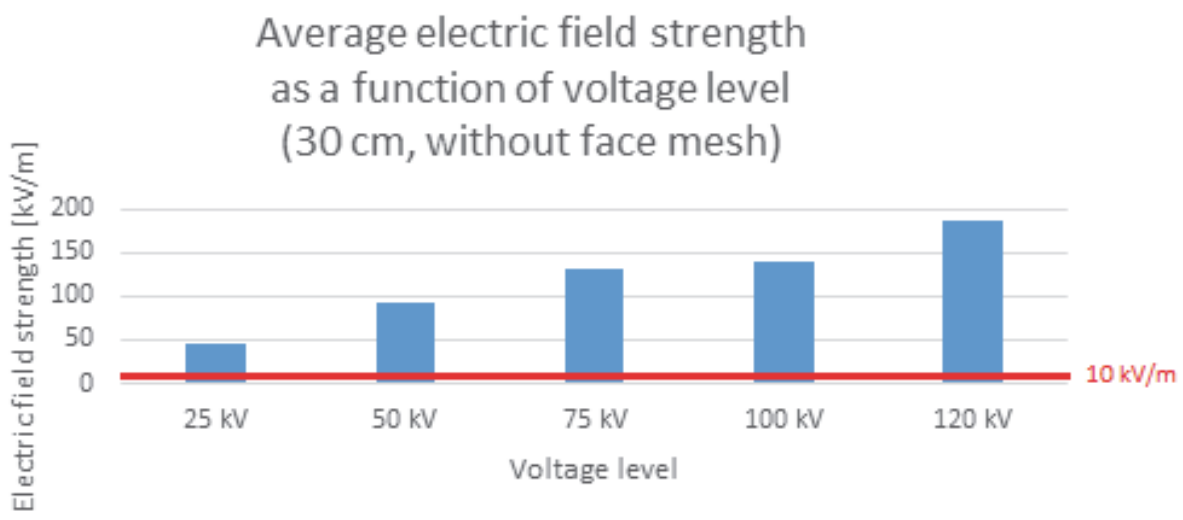

Figure 3. Electric field strength inside the conductive clothing in front of worker's face without any face mesh; laboratory measurement results (conductor-face distance: $30 \mathrm{~cm}$ )

As it can be seen in the Fig. 3, electric field was always higher than the current limit in the front of the face of the worker - even at the lowest inspected voltage level $(25 \mathrm{kV})$. The same measurement have been repeated in the same arrangement, the only difference was the application of a face mesh with an opening of $1.75 \mathrm{~cm}$ (commonly applied in Hungary as a part of Dr. Béla Csikós' technology of high voltage live-line maintenance). Electric field strength results are shown in Fig. 4. Results show that face mesh has reduced the electric field strength below the valid limits. Fig. 5 shows that this shielding effect is highly effective even in an extreme case of a distance of $1 \mathrm{~cm}$ between the face and the conductor. It can be determined that face mesh is an essential part of any kind of conductive clothing [9-13]. Using a properly designed face mesh is always necessary to ensure the proper level of protection of LLM personnel at any time of any kind of high voltage live-line work. Finite element simulations have been executed to investigate critical face mesh opening size as a function of voltage level. 


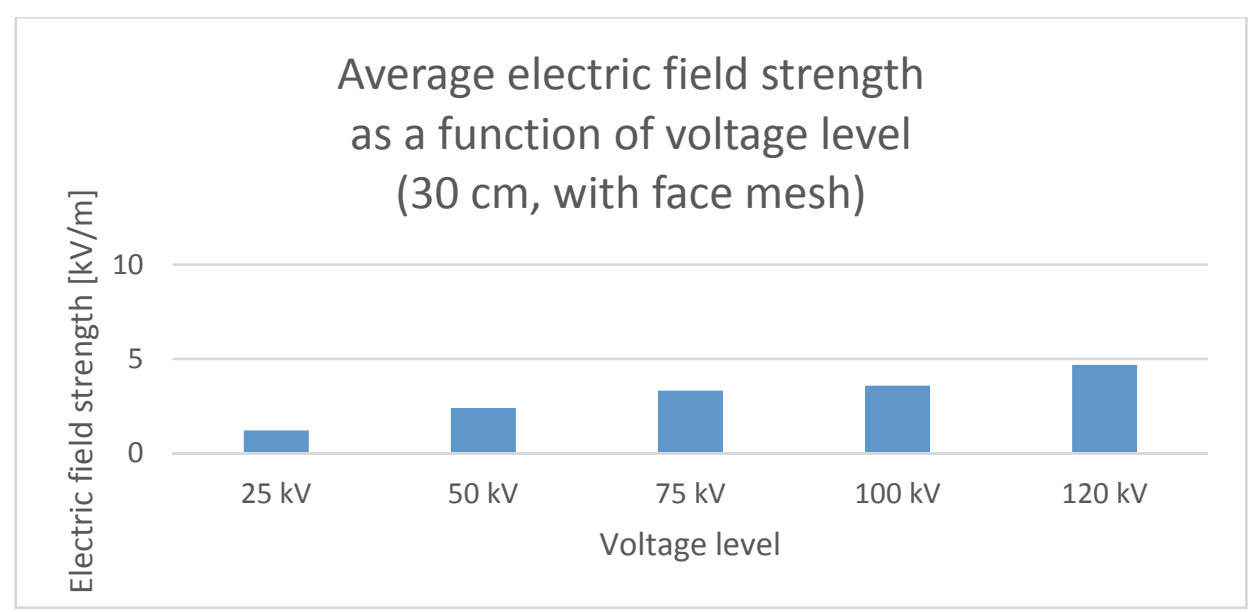

Figure 4. Electric field strength inside the conductive clothing in front of worker's face with a commonly used type of face mesh (Hungarian "Csikós", average opening size: $1.75 \mathrm{~cm}$; laboratory measurement results, conductor-face distance: $30 \mathrm{~cm}$ )

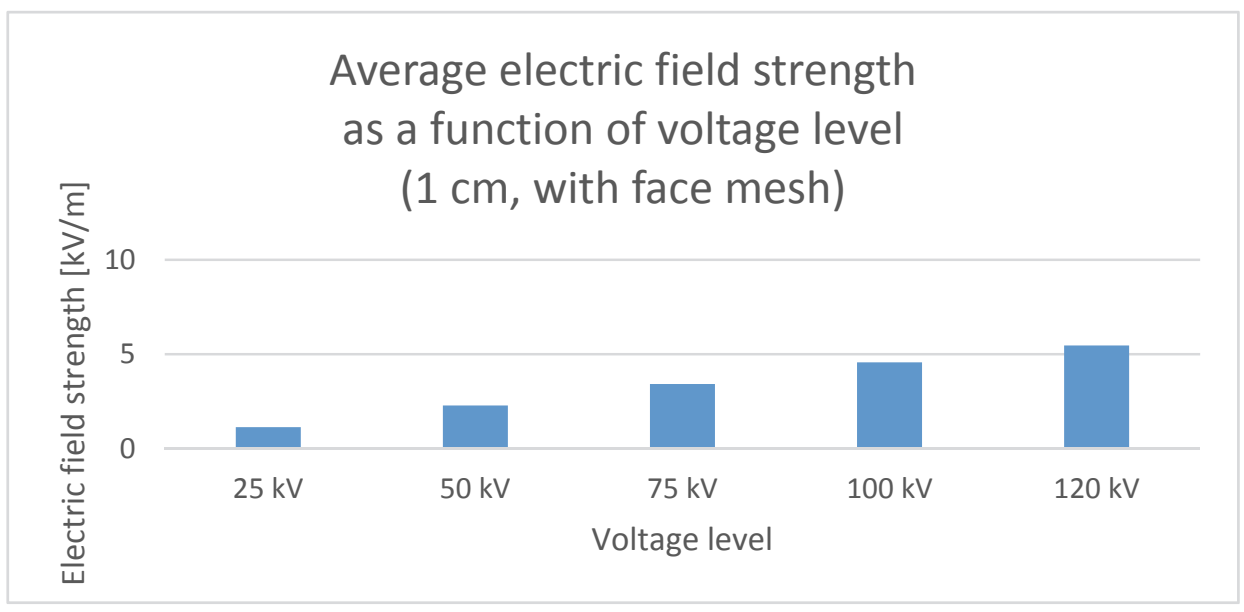

Figure 5. Electric field strength inside the conductive clothing in front of worker's face with a commonly used type of face mesh (Hungarian "Csikós", average opening size: $1.75 \mathrm{~cm}$; laboratory measurement results, conductor-face distance: $1 \mathrm{~cm}$ )

3D CAD model used for the calculations is shown in Fig. 6 (grounded structures e.g. towers in the vicinity of the working site have also been modelled). 


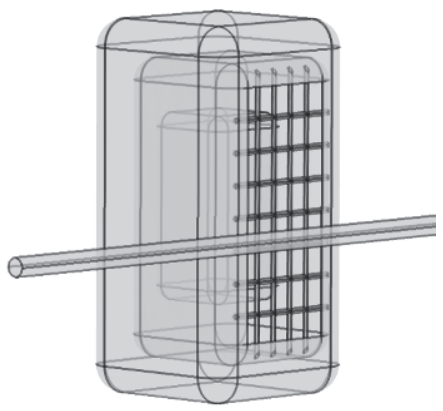

Figure 6. 3D CAD model for finite element simulations

Typical arrangements have been inspected in two cases. The first case is the approach of the phase conductor without the potential clamp being connected to the line (the potential of the conductive clothing floats). Three different mesh designs have been examined:

- A regular face mesh with an opening of $1.94 \mathrm{~cm}$ (horizontal) and $2.97 \mathrm{~cm}$ (vertical)

- A coarse face mesh with an opening of $6.82 \mathrm{~cm}$ (horizontal) and $6.44 \mathrm{~cm}$ (vertical)

- Conductive clothing without any face mesh.

During the examination of the approach of phase conductor, the distance between the line and the face of the worker was $50 \mathrm{~cm}$. The voltage level of the conductor was the phase voltage of a $400 \mathrm{kV}$ power line (about $231 \mathrm{kV}$ ). Electric field distribution is shown in Fig. 7.
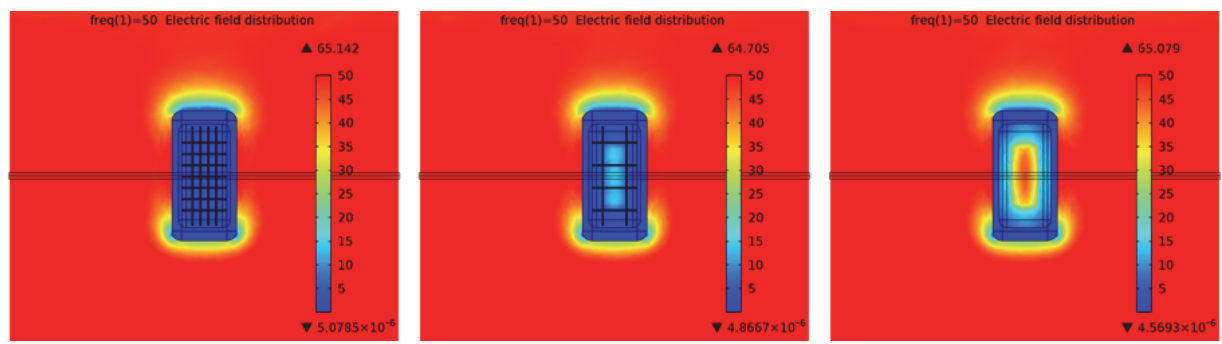

Figure 1. Electric field distribution during the approach of the conductor (from left to right: with normal, coarse and without any face mesh)

Minimal, average and maximal electric field strength values are summarized in Table 2 and in Fig. 8. 
Table 2. Minimal, average and maximal electric field strength values for each cases (conductor approach)

\begin{tabular}{|c|c|c|c|}
\hline Electic field $[\mathrm{kV} / \mathbf{m}]$ & Normal face mesh & Coarse face mesh & No face mesh \\
\hline Minimum & 0,62 & 1,49 & 6,38 \\
\hline Maximum & 2,47 & $\mathbf{1 6 , 7 3}$ & $\mathbf{4 5 , 6 8}$ \\
\hline Average & 1,59 & 6,75 & $\mathbf{2 4 , 8 9}$ \\
\hline
\end{tabular}

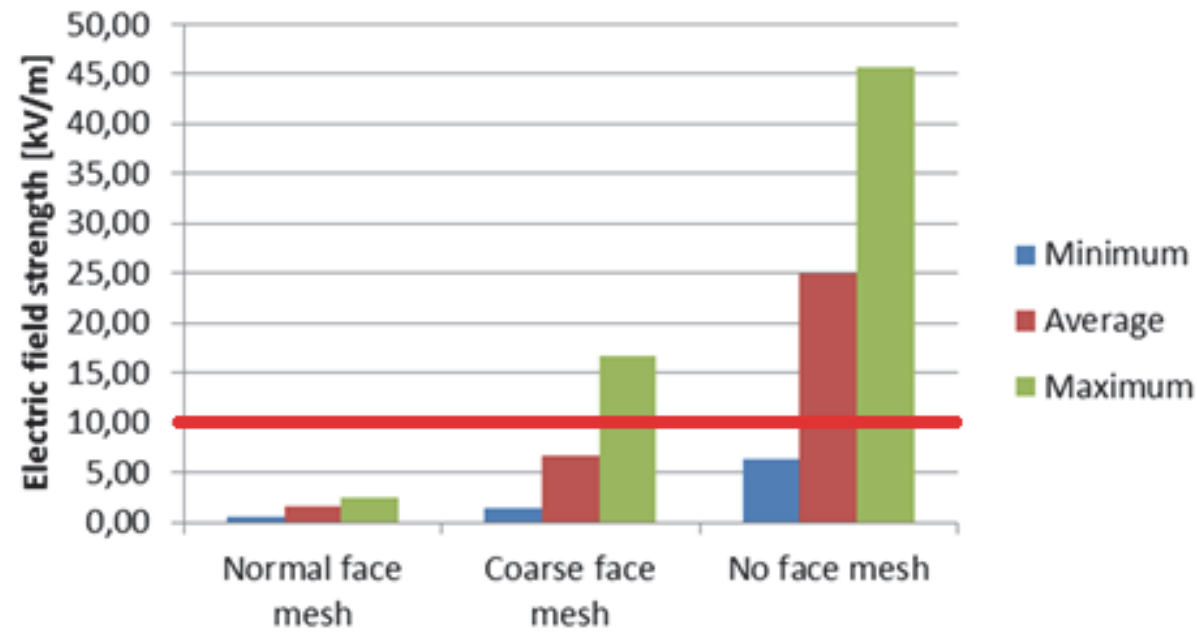

Figure 2. Values of electric field strength during the approach of the conductor

Fig. 9 shows the same cases during working at the potential of the phase conductor (with the potential clamp being connected to the line). Distance between the conductor and the face of the worker was $10 \mathrm{~cm}$ in this case. Electric field distribution is shown in Figure 9.
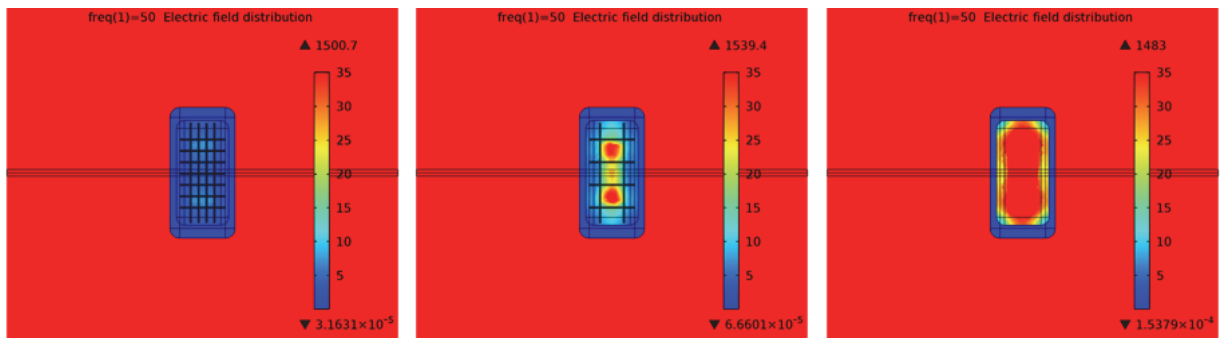

Figure 3. Electric field distribution while the conductive clothing is energized (from left to right: with normal, coarse and without any face mesh) 
Minimal, average and maximal values of electric field strength is shown in Table 3 and in Fig. 10.

Table 3. Minimal, average and maximal electric field strength values for each cases (energized clothing)

\begin{tabular}{|c|c|c|c|}
\hline Electic field $[\mathbf{k V} / \mathbf{m}]$ & Normal face mesh & Coarse face mesh & No face mesh \\
\hline Minimum & 1,70 & 4,53 & $\mathbf{2 1 , 0 5}$ \\
\hline Maximum & 8,06 & $\mathbf{4 1 , 0 3}$ & $\mathbf{1 1 2 , 9 3}$ \\
\hline Average & 4,17 & $\mathbf{1 6 , 2 3}$ & $\mathbf{6 0 , 0 0}$ \\
\hline
\end{tabular}

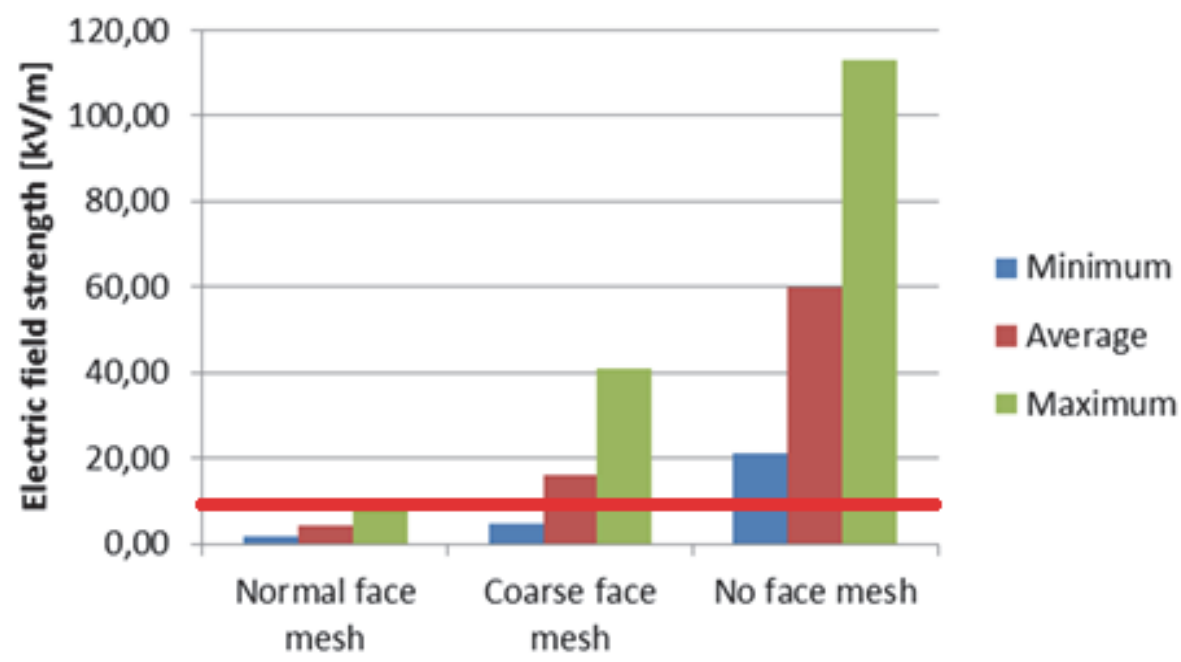

Figure 4. Values of electric field strength while the conductive clothing is energized

As it can be seen from the figures above face mesh has an essential shielding effect, which is the key of the safe work from the aspect of the protection against electric fields. Another important moral of the simulations is that mesh distribution has a significant effect on the minimal, average and maximal electric field strength values on the face of the worker during high voltage LLM.

Other simulations were executed to determine the optimal size of openings on the face mesh. Electric field strength as a function of mesh opening radius can be seen in Fig. 11 (overview) and in Fig. 12 (in the range of $0-10 \mathrm{kV} / \mathrm{m}$ ) for different nominal voltage levels (the distance between the conductor and the face was $10 \mathrm{~cm}$ ). 


\section{Maximal electric field strength \\ vs. mesh opening radius}

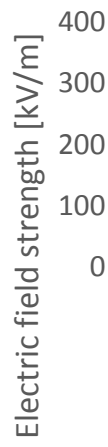

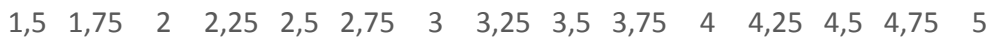
Radius of face mesh opening $[\mathrm{cm}]$

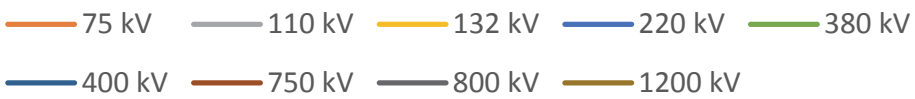

Figure 51. Electric field strength as a function of the size of mesh openings (overview)

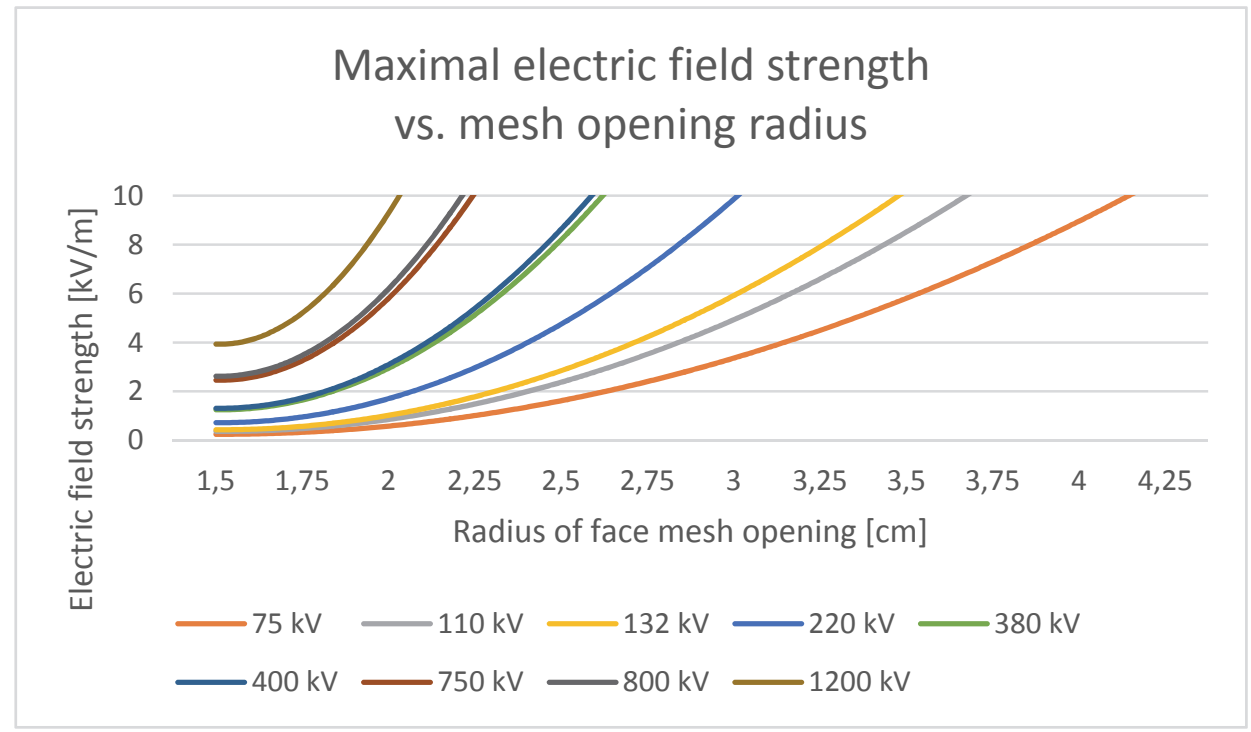

Figure 62. Electric field strength as a function of the radius of mesh openings (range of $0-10 \mathrm{kV} / \mathrm{m}$ ) 
Besides the proper electric shielding properties, other aspects have also to be taken into consideration to design a face mesh, such as visibility, ergonomics, or ventilation. In case of decrease of personal comfort, fault rate of LLM personnel might increase. This is the main reason why it is especially important to design a face mesh which keeps the electric field below the limits - even in critical cases - and guarantee proper ergonomic aspects at the same time. As it can be seen from Fig. 11 and Fig. 12, face meshes with an opening radius of $1.75 \mathrm{~cm}$ can guarantee these two criteria to meet simultaneously: electric field strength remains below $10 \mathrm{kV} / \mathrm{m}$ even in case of a voltage level of $1200 \mathrm{kV}$ and based on the practical experiences it does not have any disadvantageous effect on the accuracy of the work - even in case of long periods of activity in the vicinity of high voltage power lines.

\section{Summary}

Electric fields can be shielded effectively in practice during live-line maintenance with conductive clothing acting as a Faraday-cage [14 - 16]. To guarantee the safety of the workers strength of electric field has to be reduced below the current exposure limits defined by ICNIRP at any time of the work. Measurements and simulations executed in the High Voltage Laboratory of BUTE have proved that during normal working conditions ELF electric fields might exceed their limits, even when a given clothing pass the screening efficiency test of the valid standard. Suggestions have been made and are under consideration by the committee of IEC for the revision of the current arrangement to simulate worst-case scenarios in practice.

Only conductive clothing with a properly designed face mesh is effective enough to reduce electric field strength. Protection of the face is essential and has to be ensured to guarantee the safety of the work. Proper design reduces the electric field effectively, but ensures proper ventilation and visibility as well. A practical recommendation for face mesh opening radius has been defined in this paper.

Live-line maintenance is the future of maintenance: numerous planned activities can be executed safely, economically and without any consumer disturbance. Safety of LLM personnel can be guaranteed by properly designed and frequently inspected live-line and personal protective equipment. Safety of workers has always to be handled as a first priority during any kind of work.

\section{References}

[1] International Council on Large Electric Systems (CIGRÉ): Report 561, Live Work - A Management Perspective, Joint Working Group, B2/B3.27, December 2013.

[2] http://fab.cba.mit.edu/classes/MIT/862.06/students/alki/GA.html, date of visit: 02 February, 2015.

[3] International Commission On Non-ionizing Radiation Protection (ICNIRP): Statement, General Approach to Protection Against Non-Ionizing Radiation Protection. Health Physics 82(4):540-548, 2002.

[4] International Commission On Non-ionizing Radiation Protection (ICNIRP): Guidelines for Limiting Exposure to Time-Varying Electric and Magnetic Fields $(1 \mathrm{~Hz}-100 \mathrm{KHz})$. Health Physics 99(6):818-836, 2010. 
[5] Directive 2013/35/EU of the European Parliament and of the Council of 26 June 2013 on the minimum health and safety requirements regarding the exposure of workers to the risks arising from physical agents (electromagnetic fields) (20th individual Directive within the meaning of Article 16(1) of Directive 89/391/EEC) and repealing Directive 2004/40/EC.

[6] World Health Organization (WHO) International Agency For Research On Cancer (IARC): Monographs On The Evaluation Of Carcinogenic Risks To Humans. Volume 80, Non-Ionizing Radiation, Part 1: Static And Extremely Low-Frequency (ELF) Electric And Magnetic Fields, IARCPress, Lyon, France, 2002.

[7] Göcsei G, Németh B: New challenges in live-line maintenance. IEEE Electrical Insulation Conference, Seattle, WA, USA, 2015 (publication in progress).

[8] International Electrotechnical Commission (IEC): Live working. Conductive clothing for use at nominal voltage up to $800 \mathrm{kV}$ a.c. and $\pm 600 \mathrm{kV}$ d.c. (IEC 60895:2002 + corrigendum 2003, modified).

[9] Göcsei G, Németh B, Kiss I, Berta I: Shielding efficiency of conductive clothing in magnetic field. Journal of Electrostatics, 71:(3) pp. 392-395, 2013.

DOI: $10.1016 /$ j.elstat.2013.01.001

[10] Göcsei G, Németh B, Tarcsa D: Extra low frequency electric and magnetic fields during live-line maintenance. IEEE Electrical Insulation Conference, Ottawa, Ontario, Canada, 2013.

DOI: $10.1109 / \mathrm{EIC} .2013 .6554212$

[11] Göcsei G, Németh B, Kiss I, Berta I: Health effects of magnetic fields during liveline maintenance. International Conference on Live Maintenance (ICOLIM)

Budapest, Hungary, Paper 235, pp. 1-6, 2014.

DOI: 10.1109/ICOLIM.2014.6934329

[12] Göcsei G, Németh B, Tamus Á, Kiss I, Meixner J: Shielding efficiency of conductive clothing during live-line maintenance. International Conference on Live Maintenance (ICOLIM), Budapest, Hungary, Paper 306, pp. 1-5, 2014. DOI: 10.1109/ICOLIM.2014.6934339

[13] Göcsei G, Németh B, Tamus Z, Kiss I: Face Protection Investigation Against Electric Field On Live Line Workers (keynote). IEEE International Symposium of Electrical Insulation, San Juan, USA, pp. 535-539, 2012.

DOI: $\underline{10.1109 / \text { ELINSL.2012.6251527 }}$

[14] Hotte P, Gela G, Mitchell J. D. Jr., Lyons P.F.: Electrical performance of conductive suits. IEEE Transactions on Power Delivery, Vol. 12, No. 3, pp. 11931201, 1997.

[15] Malgesini R, Valagussa R, Villa A, Carraro R,De Donà G, Milanello C, Parizia A: Conductive clothing for live line working. International Conference on Live Maintenance (ICOLIM), Budapest, Hungary, pp. 72-75, 2014.

[16] Neira L, Pascual H, Portillo Belinchón M, Pérez F, Albanese A, Fata O, Franchini R, Burna A, Stivanello I: A research on conductive clothing for live working. International Conference on Live Maintenance (ICOLIM) Budapest, Hungary, Paper pp. 1-7, 2014 